\title{
CONTROLE DE CONVENCIONALIDE: UMA REVISÃO EPISTEMOLÓGICA À LUZ DOS PRINCÍPIOS CONSTITUCIONAIS E CONVENCIONAIS DO DEVIDO PROCESSO PENAL
}

\section{RESUMO}

JOÃO SANTOS DA COSTA*

Este trabalho objetiva tecer considerações acerca do objeto do processo penal a partir do reconhecimento do controle de convencionalidade como inerente ao seu próprio conteúdo. $\mathrm{O}$ Brasil é signatário de diversos tratados internacionais, dentre eles alguns voltados para a defesa de direitos humanos, a exemplo da Convenção Americana de Direitos Humano. A eficácia normativa destas convenções ultramarinas é, ainda, bastante relativizada pela jurisdição brasileira, ainda que se reconheça a supralegalidade dessas normas. Desse modo, propõe-se uma releitura do processo penal, no sentido de que o controle de convencionalidade seja reconhecido como um elemento próprio do conteúdo de seu conceito.

Palavras-chave: CONVENCIONALIDADE; DIREITOS HUMANOS; GARANTIAS; PROCESSO PENAL

\section{CONVENTIONAL CONTROL: AN EPISTEMOLOGYCAL REVIEW IN LIGHT OF THE CONSTITUTIONAL AND CONVENTIONAL PRINCIPLES OF THE DUE CRIMINAL PROCESS}

\begin{abstract}
This work aims to make considerations over the object of the criminal process regarding the conventionality control as inserted in its own concept. Brazil is subscriber of several international treaties, among which some are to support human rights, as an example the American Convention of Human Rights. The normative efficacy of such ultramarine conventions is, still, very relativized by the Brazilian jurisdiction, despite the recognition of their supra legal status. Thus, a rereading of the criminal process is proposed, in the sense that the conventionality control may be recognized as a proper element of the content of its concept.
\end{abstract}

Keywords: CONVENTIONALITY; HUMAN RIGHTS; GUARANTIES; CRIMINAL PROCESS

\section{INTRODUÇÃO}

O processo penal vem sendo questionado, mais que indiretamente, por camadas sociais diversas, quanto aos seus fins no quadro das ciências jurídicas. O atual Código de Processo Penal foi posto em vigor pela promulgação presidencial do Decreto Lei n ${ }^{\circ} 3.689$ de 3 de outubro

\footnotetext{
* Bacharel em Direito pela Universidade Estadual do Piauí-UESPI. Mestre em Direito pela Pontifícia Universidade Católica do Rio Grande do Sul - PUCRS. Doutorando em Ciências Criminais pela Pontifícia Universidade Católica do Rio Grande do Sul - PUCRS. Professor do curso de Direito da Centro Universitário Santo Agostinho - UNIFSA. Procurador Municipal de Timon-MA ocupando o cargo de Procurador Geral desde 2013. Atuação com ênfase em Direito nas área cível e criminal. Endereço postal: Quadra 06, Casa 04, Bela Vista I, CEP 64.030-020, Teresina-PI. Endereço eletrônico: jscostadireito@gmail.com.
} 
de 1941. Não faltaram, desde então, estudos das mais diversas áreas do conhecimento que questionassem o papel do processo penal como ramo do conhecimento jurídico que instrumentalizasse a repressão à violência.

Dentre os tantos pontos sobre os quais se têm debatido, um mereceu atenção e serve de base para a discussão que se pretende propor neste trabalho. Diz respeito à função do processo penal no contexto epistemológico, isto é, de seus fundamentos essenciais no regime democrático que se eleva como instância de conhecimento contramajoritário, fundado em garantias fundamentais e convencionais.

Pretende-se aqui propor, ainda que em breve estudo, uma abordagem do processo penal como garantia, que se efetiva por meio de princípios nucleares e fundantes de seu conceito. Trata-se de um estudo exploratório, fundado no método dedutivo de construção do conhecimento, que detém o escopo de trazer na fundamentação sólidos referenciais teóricos.

A partir da premissa de que o núcleo duro do processo penal se encontra essencialmente em colocar a proteção da pessoa humana como fim, pretende-se avançar para a abordagem crítico-filosófica sob as bases da convencionalidade. O objetivo central deste trabalho cinge-se, assim, em levantar o problema da ainda incipiente valoração convencional do processo penal brasileiro, mormente se tenha uma base teórica que remete a esta preocupação.

\section{O CONCEITO DE PROCESSO PENAL: FUNDAMENTO DE EXISTENCIA NO REGIME DEMOCRÁTICO CONSTITUCIONAL}

Quando se fala em processo é natural e, mesmo lógico, que se pense em Justiça. O processo como instrumento de justiça não é uma visão que de todo se afasta da noção que se tem construída ao longo dos estudos mais apurados sobre o tema. No entanto, é um complicador teórico exercer a pretensão de compreender o processo a partir do conceito de Justiça. Este exige uma pesquisa que permeia a história da humanidade e das relações sociais. É um conceito que certamente não cabe em si mesmo. No entanto, se tomada a expressão Justiça como poder do Estado, como jurisdição, ou juris dictio, certamente se abre um caminho a ser conduzido para a delimitação da noção de processo. Em um braço desse percurso se encontra a noção e o objeto do processo penal.

A noção de processo penal, portanto, detém como premissa constituir-se como uma manifestação da Jurisdição, do poder do Estado de aplicar uma sanção penal. Mas, como expõe 
Goldschmidt (1961, p. 16), esta é uma definição sempre nominal, que explica o objeto do processo penal, mas não explica sua essência.

A par disso, deve-se buscar o alcance do conceito de processo penal a partir de sua essência. O problema, então, está em discernir ou, de outro modo, delimitar o conteúdo desta expressão. Parafraseando Lopes Jr. (2018b) a questão é direcionada para a discussão do fundamento de existência do processo penal, o seu núcleo fundante.

A opção pela busca de uma resposta aqui não poderia ignorar uma análise do que se denomina Estado Constitucional de Direito. A proposta, então, é encontrar a base epistemológica do processo penal a partir de uma leitura constitucional de seu objeto.

No Estado de Direito uma noção essencial é a de controle do poder. Essa assertiva é encontrada, a propósito, na obra de Sarlet; Marinonnie \& Mitidiero (2017, p. 89), quando expõem que “... uma das primeiras e mais importantes funções da constituição diz com o fato de ela operar como instrumento (estatuto) de limitação e controle do poder.”. Sem embargo da complexidade do conceito de poder, tem-se aí com premissa a limitação jurídica do poder político, mas que se desdobra em duas formas: a primeira, pela divisão ou separação dos poderes, a segunda pelo estabelecimento de garantias fundamentais.

Nessa linha, tem-se em primeiro lugar, portanto, que a proteção dos direitos e garantias fundamentais se encontra na base do Estado Democrático de Direito. E onde entra, pois, o processo penal? Pensa-se, essencialmente, o processo penal como um limite ao poder de punir do Estado, especialmente com o escopo de garantir os princípios fundantes do Estado Democrático de Direito, tal como a proteção da dignidade da pessoa humana, no sentido de pessoa como um ser no mundo, com direito à vida, à liberdade, à igualdade e à integridade moral. Não por outra razão, tem também o direito a um processo penal justo, aqui tomado na expressão adotada por Chourk (2018) como devido processo constitucional-convencional. Em outros termos, também se manifesta Lopes Jr. (2018b) sobre o tema posicionando-se pela legitimidade do processo penal com escopo em sua instrumentalidade constitucional.

Assim, voltando-se para o objetivo primário da análise conceitual do processo penal tomando-se como base seu fundamento de existência, já se pode expor que este se dá no primado da garantia fundamental de realização da justiça em conformidade com o devido processo constitucional-convencional.

Essa abordagem introdutória, por certo, detém como cerne evidenciar o reconhecimento da essência do processo penal nas garantias constitucionais e convencionais à 
dignidade da pessoa humana. O direito ao devido processo penal constitui-se, assim, como um espaço democrático para a realização dos direitos e garantias da pessoa humana, tal como exposto no Art. 10 da Declaração Universal dos Direitos Humanos ${ }^{\dagger}$.

Igualmente, encontra guarida o devido processo penal no Pacto de San José da Costa Rica, ou Convenção Americana de Direitos Humanos, que estabelece um rol de garantias processuais, as quais se encontram previstas em seu Art. $8^{\circ}$, II, primeira parte, donde se extrai o direito da pessoa acusada da prática de um delito de ser presumida inocente, enquanto não for legalmente provada sua culpa.

As garantias ao devido processo penal, ora extraídas de tratados internacionais de direitos humanos, dentre elas o direito de tratamento isonômico, como o de ser julgado por um juiz ou Tribunal imparcial, além da presunção de inocência receberam no sistema jurídico interno brasileiro uma especial proteção na Constituição Federal, que as conferiu o status de direitos e garantias fundamentais.

Trazendo a discussão para o contexto da Constituição Federal brasileira, é de se constatar que esta detém um arcabouço de garantias fundamentais que se harmonizam com o que disciplina a Declaração Universal de Direitos Humanos e o Pacto de San José da Costa Rica.

A garantia ao devido processo legal, além de uma garantia da pessoa humana, é um direito fundamental explícito na Constituição Federal brasileira de 1988. De certo, esclarece Canotilho (2003, p. 378) que a fundamentalidade “... aponta para a especial dignidade dos direitos num sentido formal e num sentido material." Nessa mesma linha de intelecção, Canotilho (2003, p. 407) expõe:

A primeira função dos direitos fundamentais - sobretudo dos direitos, liberdades e garantias - é a defesa da pessoa humana e de sua dignidade perante os poderes do Estado (e de outros esquemas políticos coactivos).

Enfeixando esta análise conceitual do processo penal, faz-se novamente referência à obra de Lopes Jr. para quem o processo penal deve ser compreendido à luz da Constituição e da $\mathrm{CADH}$, enfim, colocando no devido lugar o bem jurídico que visa tutelar primordialmente, a pessoa humana. Mas, para melhor compreender esta primeira análise e sua correlação com o

\footnotetext{
† Dispõe o Art. 10 da Declaração Universal dos Direitos Humanos: “Toda a pessoa tem direito, em plena igualdade, a que a sua causa seja equitativa e publicamente julgada por um tribunal independente e imparcial que decida dos seus direitos e obrigações ou das razões de qualquer acusação em matéria penal que contra ela seja deduzida."
} 
objetivo central deste ensaio, é necessário ainda se tecer uma leitura acerca dos princípios do devido processo constitucional e convencional, como premissa para incursão na convencionalidade e sua função no sistema jurídico constitucional brasileiro, analisando de forma mais detida o controle de convencionalidade no processo penal.

\section{PRINCÍPIOS CONSTITUCIONAIS E CONVENCIONAIS DO DEVIDO PROCESSO PENAL}

\subsection{Princípio da jurisdicionalidade (ou nulla poena, nulla culpa sine judicio)}

A propósito do princípio da jurisdicionalidade, oportuno trazer a nota feita por Cordero (1986) acerca de seu monopólio, quando faz referência ao Art. 78 do Estatuto albertino ${ }^{\ddagger}$, onde constava que "la giustizia emana dal re, ed è amministrata in suo nome dai giudici che'egli istituisce $^{\text {} § . ~ C o m o ~ o b s e r v a, ~ i s s o ~ n a ̃ o ~ p a s s a ~ d e ~ u m a ~ m e t a ́ f o r a ~ i n o ́ c u a . ~ E ~ d a ́ ~ c o m o ~ e x e m p l o ~ o ~ c a s o ~}$ da França, fazendo referência à uma regra do ano de 1789, estabelecendo que «le pouvoir judiciaire ne pourra, en aucun cas, être exercé par le roi ni par le corps legislatif »"* e, ainda, «la justice sera administrée au nom du roi, par les seuls tribunaux établis par la loi, suivant les príncipes de la constituition, et selon les formes determinées par le loi $»^{\dagger \dagger}$. A ideia de jurisdição limitada pela Lei surgiu, então, como limite à 'jurisdição do rei”. O poder não emana do rei, mas da Lei. Essa foi, de fato, um conquista civilizatória do Estado Constitucional de Direito. Há, enfim, no conceito de jurisdição a pretensão de se estabelecer limites como mecanismos de manutenção da própria ordem jurídica.

No entanto, bem se sabe, por experiências tragicamente vividas pelos povos do mundo, que tais limites são por vezes extrapolados em nome da mesma ordem jurídica. A desculpa de se executar um determinado plano de restrição ou cassação de direitos e garantias, a exemplo da proteção da liberdade de própria vida, é o lugar comum do discurso antidemocrático utilitarista e eficientista de imposição da ordem jurídica sob o comando pessoal de uma liderança populista. Assim, o excesso de poder estaria justificado, e. g., pela expressão de que

\footnotetext{
‡ Trata-se do denominado "Estatuto fundamental da Monarquia de Saboya", firmado em 4 de março de 1848, por Carlos Alberto de Saboya, que a definiu como a "Lei fundamental, perpétua e irrevogável da Monarquia" e que foi substituído pela Constituição italiana de 1948.

$\S$ Em tradução livre, tem-se que "a justiça emana do rei e é administrada em seu nome pelos juízes que ele institui".

** Em tradução livre: "o judiciário não pode, sob nenhuma circunstância, ser exercido pelo rei ou pelo legislativo".

${ }^{+\dagger}$ Em tradução livre: "a justiça será administrada em nome do rei, pelos únicos tribunais estabelecidos por lei, de acordo com os princípios da constituição e de acordo com as formas determinadas por lei."
} 
“der Führer schütz das Recth” humanitárias cometidas por Hitler na Alemanha de 1934. Não tão diferente, é o discurso de Alfredo Rocco ${ }^{* * *}$, de 1926, que em defesa do fascismo, o coloca como uma doutrina da ação, do sentimento e do pensamento que deveria ser compreendida e assimilada por todos. No discurso de Rocco, ele exalta o sacrifício de todos em defesa do Estado.

A jurisdicionalidade detém, com efeito, uma relevância essencial na compreensão do processo penal. Dizer o direito, no processo penal, não significa meramente admitir o monopólio do poder de punir conferido à jurisdição estatal. É, antes de tudo, assimilar que se trata de um poder constitucionalmente delimitado pelas garantias fundamentais de proteção da pessoa humana. O indivíduo, de outro modo, tem o direito fundamental de ser julgado por um juiz investido legalmente na função mas, sobretudo, que reconheça os limites legais e constitucionais do exercício de sua função.

O processo penal, nesse caso, não é simples instrumento de justificação do exercício do poder, pelo contrário, nas palavras de Lopes Jr (2018b, p. 59).:

O juiz assume uma nova posição no Estado Democrático de Direito, e a legitimidade de sua atuação não é política, mas constitucional, consubstanciada na função de proteção dos direitos fundamentais de todos e de cada um, ainda que para isso tenha que adotar uma posição contrária à opinião da maioria. Deve tutelar o indivíduo e reparar as injustiças cometidas e absolver quando existirem provas plenas e legais (abandono completo do mito da verdade real).

A assertiva detém um desdobramento epistemológico que ultrapassa o objetivo do presente trabalho, de qualquer modo, não se pode deixar passar uma análise, ainda que perfunctória, do que vem ser o papel do juiz no Estado Democrático de Direito. Antes de tudo, somente se considera juiz o lugar prévia e legalmente constituído com competência delimitada. A propósito, diz JIMÉNEZ (1989, p. 164) que "El principal límite a la jurisdicción penal es la competencia. Pero no siempre quien tenga la primera tiene también la segunda".

A propósito, do reconhecimento do juiz como poder contramajoritário é possível, também, deduzir a sua responsabilidade como um ente extra processo, no sentido de que não é parte no processo, ou seja, é um “im-parcial”. A imparcialidade se mostra, nesse ponto, como

\footnotetext{
"¥ Em tradução livre: “O líder protege a Lei”.

§§ Disponível em < http://delete129a.blogsport.de/images/CS DerFuehrerschuetztdasRecht.pdf>. Acesso em 18.07.2020.

${ }^{* * *}$ Disponivel em < https://www.stephenhicks.org/2017/06/05/roccos-the-political-doctrine-of-fascism/>. Acesso em 18.07.2020.
} 
a força que faz do processo um operador da mudança, para usar a expressão de Martins (2013). Assim, o juiz não pode e não deve ser a voz da maioria, pelo contrário, detém a responsabilidade de tornar o processo um instrumento constitucionalmente garantista. Transcreve-se, pela pertinência, o seguinte excerto de Martins (2013, p. 100):

Por fim, o processo só será um verdadeiro operador de mudança enquanto conseguir assumir uma faceta tão impopular quanto imprescindível: ser um defraudador de expectativas.

As expectativas postas no processo penal, pelo menos no quanto se observa na realidade vivida pelo país, precisam ser repensadas. Não se fará justiça sem um processo penal no qual o juiz não detenha uma função devidamente delimitada como poder contramajoritário, apto a legitimar a própria jurisdição enquanto detentora do monopólio de decisão de um caso penal.

\subsection{Princípio acusatório}

O princípio acusatório remete ao aforismo latino nemo judex sine actore. Consoante dito em linhas anteriores, o juiz é um terceiro, estranho ao processo, portanto não pode, por vontade ou impulso próprio, provocar-se, isto é, agir ex officio. O juiz não provoca a si mesmo. Pelo caráter puramente didático, transcrevem-se as palavras de Goldschmidt (1961, p. 111):

Sin embargo, el principio "actorio", transformado luego en acusatorio, se mantiene en el proceso penal, donde el Tribunal criminal es un tribunal popular, porque de éste, por falta de permanencia y movilidad, no puede exigirse un procedimiento de oficio ni la recogida del material procesal.

Do princípio acusatório, portanto, infere-se, numa correlação lógica intrínseca, o princípio da imparcialidade. O juiz imparcial é, sobretudo, um juiz que se reconhece enquanto instância inerte, que condiciona a deflagração do rito processual e a produção de provas exclusivamente ao interesse expressamente manifestado pelas partes. E diga-se que, quando se diz que o juiz não é parte no processo, não o é no sentido material e formal.

O princípio acusatório, no entanto, remete, também, à análise do sistema acusatório e seu contraponto com denominado sistema inquisitivo. Isso é assim, porque o cerne do debate entre os dois sistemas se dá no âmbito da gestão da prova. No sistema acusatório, esta é uma prerrogativa exclusiva das partes, ao passo que no inquisitivo, o juiz detém o poder de provocar a produção da prova.

No caso do processo penal brasileiro, este é um ponto certamente delicado, cuja crítica se assenta desde a proposta do projeto da codificação vigente, cujas bases estão no Código de 
Processo Penal italiano de 1930, o denominado Código Rocco. Esclarece Coutinho (2010), a propósito, que o processo penal brasileiro sempre teve uma estrutura inquisitorial, no entanto, conforme declara, o CPP não adota um sistema puro (este não existe, com efeito), mas um sistema misto, no qual, prevalecendo as características da inquisitoriedade, se mesclam ou agregam elementos do sistema acusatório.

Reforça a marca inquisitorial do processo penal brasileiro o modelo de gestão da prova na fase pré-processual, quando se tem o inquérito policial. Consoante a práxis forense brasileira, a acusação é feita com base na prova produzida em um órgão policial, onde há a coleta de depoimento pessoal, oitiva de terceiros como "testemunhas" e realização de perícia.

Para além disso, na redação do Art. 156 do CPP, faz a lei uma distribuição da carga probatória, na máxima de que "A prova da alegação incumbirá a quem a fizer, ...”, quando a única afirmação que pode ser feita pela parte acusada é a de sua inocência, uma presunção constitucionalmente garantida, como se abordará adiante. Mais do que isso, o dispositivo em comento faculta ao juiz a produção de provas “consideradas urgentes e relevantes”, quando isso deveria ser um ônus exclusivo das partes. É fato que, qualquer que seja a atuação do juiz nesse sentido, ainda que sob os auspícios de agir bona fide, malograda estará sua imparcialidade, pois que, na essência, já produziu um juízo sobre o caso concreto.

\subsection{Princípio da presunção de inocência}

O processo penal não permite um equilíbrio de forças entre a acusação e o acusado. Aquela, que se confunde com a figura do Estado, e detém somete por isso uma posição dominante no processo. $\mathrm{O}$ acusado se porta, assim, como um hipossuficiente. A presunção de inocência, melhor expressa como presunção de não culpabilidade, tem o escopo de minimizar tal desequilíbrio. Daí advém, pois a máxima de que in dubio pro reo.

Reconheceu-se, de fato, este fim na Convenção Americana de Direitos Humanos $\mathrm{CADH}$, que estabelece: "Toda pessoa acusada de delito tem direito a que se presuma sua inocência enquanto não se comprove legalmente sua culpa.”.

A Constituição Federal acolhe o princípio da presunção de inocência em seu Art. $5^{\circ}$, LVII, ao dispor que "ninguém será considerado culpado até o trânsito em julgado de sentença penal condenatória.".

No entanto, nem sempre foi assim. Consoante explica Giacomolli (2013), na Idade Média, quando a estrutura sociopolítica era exclusivamente inquisitória e a tortura era um mecanismo de busca da verdade, não se partia da presunção de inocência do acusado, mas de 
sua culpabilidade. A prova da inocência era uma carga individual e exclusiva do acusado, que deveria demonstrá-la pela purgatio. Faz aqui lembrar a obra de Eymerich (1993, p. 208), denominada Directorium Inquisitorum, que traz uma dentre tantas práticas do juiz inquisidor:

Tortura-se o acusado que vacilar nas respostas, afirmando ora uma coisa, ora outra, sempre negando os argumentos mais fortes da acusação. Nestes casos, presume-se que esconde a verdade e que, pressionado pelo interrogatório, entra em contradição. Se negar uma vez, depois confessar e se arrepender, não será visto como "vacilante" e sim como herege penitente, sendo condenado.

A transcrição que se faz do Manual dos Inquisidores não é de todo ocasional. Tem uma finalidade bem peculiar. O Brasil tem essa prática na memória. E não é muito distante. Por mais que não se admita explicitamente a sua prática, a metodologia de interrogatórios ainda é orientada pela busca da confissão como a melhor, a mãe das provas.

As palavras de Aragoneses Alonso (1960, p. 48) bem se ajustam na ideia que ora se defende, quando expõe o seguinte: “La Justicia no tiene la misión de desplegar la personalidad del individuo, sino la de proporcionarle la libertad necessaria, para ello." De fato, revolvendo o conceito de processo penal exposto no início desde trabalho, tem-se que o devido processo penal constitucional-convencional não tem o escopo de condenar com base em confissão, à míngua das garantias da ampla defesa e do contraditório.

\subsection{Princípios do contraditório e da ampla defesa}

São garantias fundamentais processuais que sempre aparecem juntas, certamente por razões óbvias. O contraditório se dá pelo acesso à ampla defesa e vice-versa. Por certo que, no Estado constitucional de direito, não se faz um processo justo sem que as partes tenham a efetiva oportunidade de manifestação processual, além da liberdade de produzir as provas necessárias à salvaguarda de seus direitos.

Na Declaração Universal dos Direitos Humanos, consta que toda pessoa acusada da prática de um crime tem direito a um julgamento público, no qual lhe sejam asseguradas todas as garantias necessárias à sua defesa. E na Convenção Americana de Direitos Humanos, temse, entre as garantias processuais mínimas, a concessão de tempo e meios adequados à preparação da sua defesa, além do direito de autodefesa ou de assistência de um defensor que a faça tecnicamente.

O contraditório e a ampla defesa constituem um aspecto intrínseco do próprio processo, no sentido mais amplo do termo, sendo irrelevante que se desenvolva perante uma autoridade judiciária ou administrativa (Art. $5^{\circ}, \mathrm{LV}$, da $\mathrm{CF} / 88$ ). Assim, é fato que, no processo 
penal, diante do bem jurídico em risco, que é a liberdade do indivíduo, tais garantias detêm uma especial relevância.

Tecendo algumas palavras sobre o contraditório, é importante ter presente que deve ser visto no âmbito da dialética inter partes, sob o enfoque da isonomia processual. No entanto, aí não se exaure. Mormente se encontre o juiz como um estranho na relação processual, no sentido de que não é parte, considerar a simples bipolaridade é reduzir por demasiado a própria complexidade do processo.

O contraditório deve ser visto, de outro modo, como uma garantia a uma decisão judicial construída com o prévio conhecimento de todo o processo. As partes devem ter a oportunidade de se manifestar sobre todos os fatos (ou acontecimentos) do processo, de modo a evitar uma "decisão surpresa". Posta a questão assim, é de se entender que o contraditório é uma limitação à atuação do juiz, voltada especialmente para coibir arbitrariedades, mas, ao mesmo tempo, serve para dar legitimação de sua atuação como instância de poder decisório. Tal como coloca Lopes Jr. (2018a, p. 98):

O juiz deve dar "ouvida" às partes, sob pena de parcialidade, na medida em que conheceu apenas metade do que deveria ter concedido. [...] Ou seja, o contraditório é observado quando se criam as condições ideais de fala e oitiva da outra parte, ainda que ela não queira utilizar-se de tal faculdade.

No processo penal, de regra, o contraditório deve ser prévio. No entanto, sabe-se bem que a sua forma diferida ou postergada se tornou quase um lugar comum na aplicação de prisão preventiva (Art. 312, CPP) e temporária (Lei 7.960/89). No entanto, na linha de entendimento que se projeta neste ensaio, defende-se inconvencional e inconstitucional, por ofensa aos princípios do contraditório e da ampla defesa, a possibilidade de se aplicar sumariamente a condenação na fase de recebimento da denúncia, ainda que constem dos autos confissão obtida na fase preliminar, diante de autoridade judicial, e outros elementos de prova (indícios).

A defesa pessoal decorre de um exercício de resistência manifestado pela própria pessoa acusada, que o faz como corolário do direito de não ter que produzir prova contra si mesmo (nemo tenetur se detegere), reconhecido como princípio da vedação da autoincriminação, ou do direito ao silêncio. Na Convenção Americana de Direitos Humanos, encontra-se expresso como o direito de qualquer pessoa de não ser obrigada a depor contra si mesma, nem, igualmente, de declarar-se culpada (Art. 8, 2, g). Na Constituição Federal brasileira, o direito ao silêncio, uma face do nemo tenetur se detegere encontra-se positivado no Art. $5^{\circ}$, XLIII. 
O alcance do nemo tenetur diz respeito à produção de qualquer espécie de prova. Não se admite, por certo, que se presuma qualquer prejuízo ao exercício de resistência do sujeito acusado quando este não colabora com a produção de provas no processo penal. Assim, o próprio silêncio não pode ser, em qualquer hipótese, interpretado em desfavor da defesa, consoante a redação do Art. 186, parágrafo único, do CPP. A propósito, diz Choukr (2018, p. 81): "Uma das grandes consequências do nemo tenetur é a impossibilidade de compelir-se a pessoa submetida à persecução que seja obrigada a colaborar na produção de provas a seu desfavor, sejam invasivas ou não."

Ao abordar o tema, Lopes Jr. (2018a, p. 101 ) o faz destacando que a defesa pessoal pode ocorrer de forma positiva e negativa. Na primeira hipótese, o indivíduo acusado atua trazendo elementos, motivos, justificativas ou mesmo a declaração negativa de autoria, circunstâncias que se apresentam especialmente em seu interrogatório, quer na fase de investigação ou mesmo na instrução processual. O seguinte excerto reflete bem esta opinião:

A autodefesa positiva deve ser compreendida como o direito disponível do sujeito passivo de praticar atos, declarar, constituir defensor, submeter-se a intervenções corporais, participar de acareações, reconhecimento etc. Em suma, praticar todos os atos dirigidos a resistir ao poder de investigar do Estado, fazendo valer seu direito de liberdade. (LOPES JR., p. 101)

No que diz respeito à autodefesa pessoal negativa, nesta se encontra o direito ao silêncio, ou mesmo de não colaborar com a investigação, sem que isso lhe traga qualquer prejuízo.

Outro ponto relevante nessa discussão diz respeito à defesa técnica. Esta é reconhecida como um direito indisponível, inclusive consagrado na Convenção Americana de Direitos Humanos $^{\dagger \dagger \dagger}$. Trata-se de garantia que reconhece na pessoa acusada um status de hipossuficiência em relação à posição do Estado-acusador, inclusive amplamente reconhecida e confirmada por precedentes do Supremo Tribunal Federal, valendo aqui referência à Súmula 523, cujo texto é o seguinte: "No processo penal, a falta da defesa constitui nulidade absoluta, mas a sua deficiência só o anulará se houver prova de prejuízo para o réu."

\footnotetext{
${ }^{+++}$Diz o Art. 8ㅇ, 2, e da CADH: “direito irrenunciável de ser assistido por um defensor proporcionado pelo Estado, remunerado ou não, segundo a legislação interna, se o acusado não se defender ele próprio nem nomear defensor dentro do prazo estabelecido pela lei;"

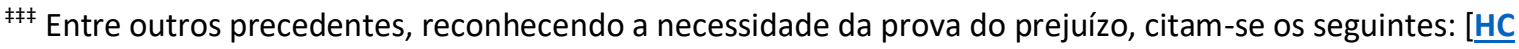
144.018 AgR, rel. min. Alexandre de Moraes, 1a T, j. 7-11-2017, DJE 261 de 17-11-2017.]. [HC 138.121 AgR, rel. min. Ricardo Lewandowski, 2a T, j. 16-10-2017, DJE 247 de 27-10-2017.]. [RHC 138.752, rel. min. Dias Toffoli, 2a T, j. 4-4-2017, DJE 143 de 27-4-2017.].
} 
O direito de defesa irradia efeitos sobre toda a dialeticidade do processo e estabelece uma simetria constitucionalmente instrumentalizada pelo mais amplo conhecimento dos fatos processuais. E a defesa técnica serve exatamente para cumprir tal mister. Para alcançar tal fim, a Constituição Federal estabelece como garantia fundamental que este, à míngua de não poder arcar com os custos, seja assistido gratuitamente (Art. $5^{\circ}$, LXXIV).

\subsection{Princípio da motivação das decisões judiciais}

Tem-se aqui mais uma garantia fundamental do devido processo penal e que tem estreita relação com o princípio da imparcialidade. Parafraseando Alonso (1960), ao fazer referência ao conhecido discurso de Werner Goldschmidt em homenagem a James Goldschmidt ${ }^{\S \S}$, pode-se ter presente que a imparcialidade consiste, na verdade, em uma espécie determinada de motivação, na declaração de uma resolução orientada pelo desejo de dizer a verdade, enfim de "colocar entre parênteses" todas as considerações subjetivas do julgador.

Mas nem sempre foi assim. Em algumas monarquias do medievo, quando prevaleciam os juízos de Deus, pelos quais o rei exerceria na Terra poderes divinos, a motivação era, por razões lógicas, ignorada. Com efeito, a ausência de motivação era uma expressão do poder absoluto monárquico, pois que subtraía a total possibilidade de se questionar o julgamento. Esta circunstância sofreu alterações no tempo e no espaço e, à medida que se consolida o regime democrático de Direito, a motivação se torna um dever do órgão julgador, tal como com assevera Choukr (2018). Para Gomes Filho (2001), os contornos da necessidade da motivação das decisões se delineiam a partir da legislação revolucionária francesa, por influência das concepções iluministas as quais avançaram no constitucionalismo do séc. XIX.

Sem a pretensão de traçar um histórico sobre o tema, deve-se ter presente que a motivação das decisões judicias, no momento atual, em que o país se submete à Constituição Federal de 1988, é um requisito de validade da própria decisão ao impor que ela seja devidamente fundamentada (Art. 93, IX). O “devidamente" é uma modificação adverbial que, na visão ora defendida, deve acompanhar o verbo "fundamentar". É, não obstante, um conceito aberto, uma cláusula indeterminada, no processo penal. Não existem, por certo, parâmetros normativos que digam quando uma decisão se encontra efetiva, razoável, ou devidamente fundamentada. Tudo o que se tem até agora é fruto de construção doutrinária e jurisprudencial.

$\S \S \S$ GOLDSCHMIDT, Werner. La imparcialidad como principio básico del proceso (la partialidad y la parcialidad). Disponível em < http://www.academiadederecho.org/upload/biblio/contenidos/la imparcialidad.pdf $>$. Acesso em 22.07.2020. 
De qualquer modo, no sentido de reconhecer a instrumentalidade constitucional e convencional do processo penal, é de todo necessário que a decisão, aqui no sentido mais específico de condenação, reflita um resultado justo, isto é, que garanta, sobretudo, o respeito às garantias processuais. Choukr (2018) faz, por sinal, uma estreita correlação entre o princípio constitucional da motivação e outros princípios constitucionais do devido processo, a saber: a) a independência do juiz; b) a legalidade das decisões e da verdade processual; c) dos direitos de ação e defesa.

Chama a atenção, pela pertinência com o problema teórico aqui debatido, a repercussão da ausência de motivação no direito de defesa, notadamente quando se pensa que poderia haver uma condenação fundada em confissão judicial, ainda que "reforçada" por outros elementos de prova constantes dos autos. Enfim, questiona-se quanto ao fato de se proceder uma decisão que não seja exauriente das circunstâncias elencadas delimitadoras da imputação constantes da peça acusatória. É, com efeito, tema que será melhor abordado logo adiante.

A propósito dessa discussão, o controle de convencionalidade surge como um plus no embate à resistência autoritária que permeia o processo penal brasileiro. O trabalho de Valério Mazzuoli (2018), pioneiro no assunto, é apenas um marco na defesa da efetivação dos direitos humanos, e isso inclui as garantias judiciais, como o status de normas constitucionais.

\section{PROCESSO PENAL E CONTROLE DE CONVENCIONALIDADE: UMA ANÁLISE EPISTEMOLÓGICA}

O cerne da discussão ora proposta foi estabelecer a convencionalidade como um fundamento epistemológico do processo penal de modo a justificar o controle de convencionalidade como mais uma garantia do processo penal em seu fim de produzir uma decisão justa. Tanto o estudo do conceito do processo penal como de seus princípios fundantes foi realizado sob esta premissa metodológica. Propõe-se, nessa parte do trabalho, pois, aprofundar a compreensão dessa análise, que se apresenta como ponto de partida para a valoração desse essencial ramo do conhecimento no sistema de garantias do devido processo penal no Estado Democrático de Direito.

Antes de adentrar no tema do controle de convencionalidade, é necessário fazer uma breve incursão acerca do que se compreende por epistemologia. Rescher (2003) descreve já na introdução de sua consolidada pesquisa acerca de epistemologia que esta detém, como missão, enquanto teoria do conhecimento, esclarecer o que se tem por conhecimento, como se dá a sua 
aplicação e porque lhe conferem os aspectos que o tornam isso, o conhecimento ${ }^{* * * *}$. Mas essa abordagem, sem dúvida, não traduz a essência do sentido de epistemologia, nem pretende fazêlo. É não mais do que um norte que simplifica a concepção de epistemologia a partir de um ponto específico: explicar o próprio conhecimento. É neste sentido, por certo, que se utiliza o termo epistemologia na maioria dos casos, como ciência (qualificada) do conhecimento. No entanto, questionar o conhecimento sob esta perspectiva não é o objeto deste trabalho. O que se tem em mente aqui é, antes de tudo, compreender que o processo penal é conhecimento. A partir desse ponto, acrescenta-se, para além da sua base conceitual e principiológica, já debatida, uma breve análise do controle de convencionalidade.

E como todo conhecimento, o processo penal detém, como escopo próprio, um objeto. Questionar e justificar este objeto se torna relevante, como já discutido neste trabalho, para compreender e justificar sua autonomia científica. O controle de convencionalidade surge, nesse sentir, como mais um elemento a reforçar o que se pode colocar como uma justificação do processo penal como parte de um sistema do conhecimento maior, que consiste o Direito, e cujo objeto é legitimar o exercício do poder punitivo estatal. O processo penal detém, pois, dentre outros fins, a efetivação de direitos e garantias que, sobretudo, se amoldam ao arcabouço normativo de proteção dos direitos humanos.

Assim, é necessário delimitar o discurso sobre o qual se questionará o processo penal a fim de tornar isso uma questão epistêmica passível de apreciação nos limites desse trabalho. É nesse ponto que se quer levantar o problema do reconhecimento da convencionalidade como uma questão epistêmica do processo penal, que justifica a sua existência. E disso construir o entendimento de que o controle de convencionalidade é uma garantia do devido processo penal no regime democrático brasileiro.

Posta esta premissa, põe-se como necessário tecer considerações acerca da convencionalidade no sistema jurídico brasileiro e, especificamente, na conformação do processo penal. A convencionalidade se tornou, modernamente, uma característica sistêmica dos regimes democráticos. Diz respeito à normatização e efetivação de garantias fundamentais voltadas para a tutela jurídica da dignidade da pessoa humana.

\footnotetext{
${ }^{* * * *}$ No original, tem-se o seguinte texto: "The mission of epistemology, the theory of knowledge, is to clarify what the conception of knowledge involves, how it is applied, and to explain why it has the features it does." (Rescher, 2003, p. xiii)
} 
A propósito do tema da proteção da dignidade da pessoa humana, um conceito complexo cuja discussão não cabe no presente estudo, concorda-se com Sarlet (2013b) para quem a dignidade detém dimensões, podendo-se falar em uma dimensão ontológica, em outra comunicativa e intersubjetiva, ainda outra como construção de desenvolvimento. Neste estudo, no entanto, se confere destaque à dimensão da dignidade como limite e como tarefa, pela qual se fala em dimensão negativa e prestativa da dignidade. Conforme as palavras de Sarlet (2013b, p. 32):

É justamente nesse sentido que assume particular relevância a constatação de que a dignidade da pessoa humana é simultaneamente limite e tarefa dos poderes estatais e, no nosso sentir, da comunidade em geral, de todos e de cada um, condição dúplice esta que também aponta para uma paralela e conexa dimensão defensiva e prestacional da dignidade.

Nesse contexto, portanto, a dignidade da pessoa humana se torna um conceito factível na cultura e realidade social. É uma tarefa no aspecto positivo, que impõe ao Estado a execução de serviços, de prestações destinadas à salvaguarda da pessoa humana em seus valores ontológicos, biológicos, subjetivos e intersubjetivos. Ao mesmo tempo, impõe uma prestação negativa, que se observa na abstenção de causar danos em impedir o pleno desenvolvimento da pessoa no meio social. É nesse âmbito globalizado de proteção da pessoa humana que se apresenta a convencionalidade, que remete aos tratados internacionais, pactos entre nações que elevam a dignidade da pessoa humana a status de núcleo fundante.

Na Constituição Federal de 1988 a adoção dos direitos e garantias previstos em tratados internacionais de direitos humanos encontra expressa previsão no Art. $5^{\circ}$, $\S 2^{\circ}$ e $3^{\circ}$. Dá-se destaque aqui ao texto do Art. $5, \S 2^{\circ}$ da $\mathrm{CF}$, que confere eficácia interna aos tratados internacionais em que a República Federativa do Brasil seja parte. Na interpretação desse dispositivo, Sarlet (2014) identifica o denominado bloco de constitucionalidade, expressão oriundo do direito constitucional francês, a qual consiste em reconhecer dois grandes grupos de direitos e garantias fundamentais: a) aqueles expressamente positivados e, também, os dispersos da Constituição, abrangendo os direitos expressamente reconhecidos e tutelados pelos tratados internacionais de direitos humanos ratificados pelo Brasil; b) os direitos decorrentes do regime dos princípios (ou direitos implícitos). São os assim chamados direitos e garantias materialmente constitucionais.

No que diz respeito aos tratados ratificados pelo Brasil, tem-se, dentre os exemplos que merecem uma nota específica, a Convenção Americana sobre Direitos Humanos (Pacto de 
São José da Costa Rica), de 22 de novembro de 1969, que foi promulgada pelo Decreto $\mathrm{n}^{\circ}$ 678, de 6 de novembro de 1992. É desse tratado internacional que são extraídas as garantias fundamentais do processo penal. Não menos relevante, e que merece detida atenção é o Pacto Internacional sobre Direitos Civis e Políticos, promulgado pelo Decreto $n^{\circ}$ 592, de 6 de julho de 1992. Essa norma convencional compõe a denominada Carta Internacional dos Direitos Humanos (ou International Bill of Rights), como esclarece Flávia Piovesan (2007).

Também, não se pode deixar de abordar o Art. $5^{\circ}, \S 3^{\circ}$ da Constituição, que foi produto da Emenda Constitucional nº 45/2004 e, como esclarece Mazzuoli (2014), é complementar em relação ao $\S 2^{\circ}$ do mesmo dispositivo, e que diz respeito às normas convencionais material e formalmente constitucionais. Isso porque disciplina o critério de equivalência das normas constantes de tratados internacionais ao status de emendas constitucionais. Críticas, no entanto, não faltaram a este pensamento. Traz-se, v. g., a opinião de Mazzuoli (2014, p. 519):

É necessário atentar ainda que o $\S 2^{\circ}$ do art. $5^{\circ}$ da Constituição já admite o ingresso dos tratados de direitos humanos no mesmo grau hierárquico das normas constitucionais, não sendo necessário outro parágrafo do artigo fazê-lo.

De modo específico, a interpretação do Art. $5, \S \S 2^{\circ}$ e $3^{\circ}$ da Constituição remete à análise da divergência inicialmente instalada no plano interno quanto ao status hierárquico das normas protetoras de direitos humanos previstas em tratados internacionais, principalmente por conta da distinção que se fez entre normas material e formalmente constitucionais. E, uma vez superado este ponto, é que se falará, então de controle jurisdicional de convencionalidade.

O julgamento do RE 466.343 pelo STF foi paradigmático quanto à análise do status das normas de direitos humanos previstas em tratados ratificado pelo Brasil. O objeto do processo é discutir a constitucionalidade e convencionalidade da prisão civil do depositário infiel. A conclusão do julgamento restou a atribuição do status de norma supralegal aos tratados internacionais de direitos humanos.

Dessa supralegalidade dos tratados internacionais de direitos humanos depreende-se que se sobrepõem à legislação infraconstitucional. Como explica Sarlet (2013a, p. 1.374):

Isso significa que a lei, nesta dimensão, está submetida a novos limites materiais, postos nos direitos humanos albergados nos tratados internacionais, o que revela que o Estado contemporâneo - que se relaciona, em recíproca colaboração, com outros Estados constitucionais inserido numa comunidade tem capacidade de controlar a legitimidade da lei em face dos direitos humanos tutelados no País e na comunidade latino-americana. 
Os limites materiais a que se refere Ingo Sarlet no excerto transcrito são, na essência, o significante do controle de convencionalidade. Eles irradiam efeitos concretos (ou significado) sobre o poder jurisdicional, último intérprete e aplicador do Direito, como se evidenciou ao abordar o princípio da jurisdicionalidade.

Elucida Giacomolli (2016, p. 13) que a leitura convencional e constitucional do processo penal constitui “... um dos pilares a sustentar o processo penal humanitário”. A propósito disso, as garantias processuais penais constantes dos tratados de direitos humanos ratificados pelo Brasil se inserem no já denominado bloco de constitucionalidade. E mais uma vez revolvendo a questão do fundamento do processo penal e de seus princípios fundamentais, não se pode abrir mão da salvaguarda de uma tutela jurisdicional efetiva, isto é, a que dê a devida efetividade à proteção do ser humano.

A norma processual penal, enquanto legislação ordinária passa, assim, por um duplo controle material vertical, segundo Giacomolli (2016), o de conformidade com as normas internacionais de proteção do ser humano (convencionalidade) e, também, sua harmonia com a Constituição Federal.

Embora se cogite quanto à possibilidade de controle concreto de convencionalidade de leis internas do país ${ }^{\dagger \dagger \dagger}$, tal circunstância cinge-se à hipótese em que o tratado internacional incorpora-se no plano interno no mecanismo disciplinado no art. $5^{\circ}, \S 3^{\circ}$ da $\mathrm{CF}$, isto é, quando passarem pelo rito de votação e promulgação de emendas constitucionais (aprovados, em cada Casa do Congresso Nacional, em dois turnos, por três quintos dos votos dos respectivos membros). No momento, pode-se dar como exemplo de norma internacional que tenha se submetido a este rito a Convenção sobre os Direitos das Pessoas com Deficiência, promulgado pelo Decreto Legislativo de $n^{\circ} 186 / 2008$.

Por outro lado, os tratados que possuem o status de norma supralegal permitem a arguição de inconvencionalidade por meio de controle difuso, de modo que qualquer juiz ou

\footnotetext{
${ }^{++++}$Seria, então, hipótese de cabimento de Ação Declaratória de Inconvencionalidade, de Ação Declaratória de Convencionalidade, ou mesmo de Ação de Descumprimento de Preceito Fundamental.
} 


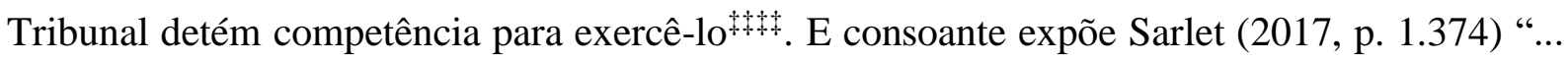
é um dever do juiz nacional, podendo ser feito a requerimento ou mesmo de ofício.". $\$ \S \S$

A propósito, não é incomum encontrar-se argumentos como o de que as regras constantes do Pacto Internacional de São José da Costa Rica são desprovidas de qualquer valor jurídico, não possuindo efeito vinculante, mas função meramente instrutória. Trata-se, com efeito, de um entendimento retrógrado e que haverá de passar por uma ressignificação. De outro modo, a linha de entendimento que se procura defender aqui converge com a tese de Mazzuoli (2018), para quem os tratados de direitos humanos as quais o Brasil aderiu, a exemplo da Convenção Americana de Direitos Humanos, detém o status de norma constitucional que irradia seus efeitos sobre todo os sistema jurídico. O Direito, enquanto ciência cultural, não pode ser estancado por argumentos reducionistas, ainda mais quando se tem em jogo a defesa de direitos e garantias fundamentais, necessários à existência do ser humano como ser social. Esta é a ideia que, pensa-se, deva ser estendida ao direito processual penal.

\section{CONSIDERAÇÕES FINAIS}

A proposta de escrever sobre a epistemologia do processo penal não foi exercício de uma escolha fácil. Criticar o conhecimento é sempre uma tarefa árdua. A dificuldade ganha contornos mais específicos quanto se busca tecer incursão crítica sobre um tema que detém relevante porosidade teórica, mormente existam vastos estudos sobre o assunto. Fala-se, nesse sentido, do controle de convencionalidade no processo penal, sua admissibilidade e contornos de efetivação.

Historicamente, a origem do processo penal brasileiro encontra-se vinculada a uma ideologia autoritária, no sentido de que o fim deve justificar os meios. Nisso, o processo penal assumiria a função de combater a criminalidade, ao lado do direito penal. O problema é que, ao se colocar a segurança pública, ou se sentir seguro, como era o discurso da ideologia fascista italiana dos primeiros decênios do século passado, as garantias processuais do devido processo,

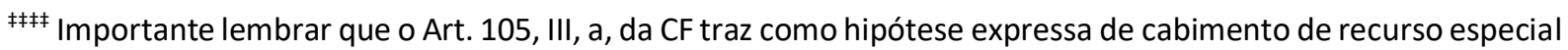
a decisão que contrariar um tratado. No plano externo, há vários precedentes que reconhecem a atuação de ofício do juiz, em qualquer instância ou tribunal, na aplicação do controle de convencionalidade, a exemplo do caso Cabrera García e Montiel Flores vs. México, citado por Giacomolli (2016, p. 31).

§§§ Giacomolli (2016) acrescenta que é possível se arguir a inconvencionalidade perante a Comissão Interamericana de Direitos Humanos - CIDH, órgão da Organização dos Estados Americanos - OEA, que tem sede em Washington e que é responsável por receber reclamações individuais, coletivas ou de entidades não governamentais.
} 
como contraditório, ampla defesa, competência previamente fixada em lei e presunção de inocência certamente se relativizam, abrindo margem para uma eficiência processual pautada na condenação, em especial a que se concretiza em prisão.

O presente trabalho buscou, em sua primeira parte, demostrar que essa visão do processo penal é equivocada, que na essência de seu conceito, encontra-se como fundamento a obtenção, antes de tudo, de uma decisão justa. Esta, a partir do reconhecimento da dignidade da pessoa humana como um princípio de normatividade específica e efetiva, somente alcançará tal status quando se submeter ao sistema internacional de tutela dos direitos humanos. O processo penal, assim, assume um aspecto predominantemente humanitário, e se eleva à condição de devido processo constitucional e convencional.

Enfim, na lógica, ainda que não linear, do raciocínio que se buscou desenvolver no presente estudo, acaba-se por reconhecer a normatividade constitucional e convencional do processo penal, de modo que, enquanto sistema regido por lei infraconstitucional, deve submeter-se a um controle jurisdicional de convencionalidade. Este, por sua vez, funda-se na hierarquia formal e material das garantias convencionais do devido processo presentes nos tratados internacionais ratificados pelo Brasil. O poder jurisdicional, materializado na figura do juiz, é submisso e devedor da eficácia dessas garantias convencionais. Trata-se, como dito em outras linhas, de uma proposta de análise epistemológica, uma crítica ao conhecimento, mas que já conquista uma embasada fundamentação teórica.

\section{REFERÊNCIAS}

ALONSO, Pedro Aragoneses. Processo y derecho processal (Introducion). 2 ed. Madrid: Editorales de Derecho Reunidas, 1960.

CHOUKR, Falzi Hassan. Iniciação ao Processo Penal. 2 ed. Florianópolis: Tiran lo Blanch, 2018.

CORDERO, Franco. Guida ala prodecura penale. Torino: Unione Tipografico - Editrice Torinese, 1986.

COUTINHO, Jacinto Nelson de Miranda. Sistema acusatório: cada parte no lugar constitucionalmente demarcado. In: $O$ novo processo penal à luz da Constituição. Coutinho, Jacinto Nelson de Miranda; Carvalho, Luis Gustavo Grandinetti Castanho de. (Org.). Rio de Janeiro: Lumen Juris, 2010, p. 1-17.

EYMERICH, Nicolau. Manual dos inquisidores - 1376. Francisco de La Peña (Revisão, 1578); Maria José Lopes da Silva (Trad.). Rio de Janeiro: Rosa dos Ventos; Brasília, DF: Fundação Universidade de Brasília, 1993. 
FOUCAULT, Michel. Microfísica do Poder. Roberto Machado (organização, introdução e revisão técnica). $4^{\text {a }}$ ed. Rio de Janeiro: Paz e Terra, 2016.

GIACOMOLLI, Nereu José. O devido Processo Penal. 3 ed. São Paulo: Atlas (Gen), 2016.

In: CANOTILHO, J. J. Gomes. MENDES, Gilmar Ferreira. SARLET, Ingo Wolfgang. STRECK, Lenio Luiz. LEONCY, Léo Ferreira (Cord.). Comentários à Constituição do Brasil. 1 ed. São Paulo: Saraiva, 2014, p. 440-445.

GLOECKNER, Ricardo Jacobsen. Nulidades no Processo Penal. 3 ed. São Paulo: Saraiva, 2018.

GOLDSCHMIDT, James. Principios generales del processo. Buenos Aires: Ediciones Juridicas Europa-America, 1961, Vol. II.

GOLDSCHMIDT, Werner. La imparcialidad como principio básico del proceso (la $\begin{array}{llllll}\text { partialidad } & \mathbf{y} & \text { la } & \text { parcialidad). } & \text { Disponível em }\end{array}$ http://www.academiadederecho.org/upload/biblio/contenidos/la imparcialidad.pdf $>$. Acesso em 22.07.2019.

GOMES FILHO, Antônio Magalhães. Motivação das decisões penais. São Paulo: Revista dos Tribunais, 2001.

JIMÉNEZ, Hernando Londoño. Tratado de Derecho Procesal Penal: principios rectores, de las acciones y sujetos procesales - Tomo I. Bogotá: Colombia, 1989.

LOPES JR., Aury. Direito Processual Penal. 15 ed. São Paulo: Saraiva, 2018a.

Fundamentos do Processo Penal: introdução crítica. São Paulo: Saraiva, 2018b.

MARTINHS, Rui Cunha. A hora dos cadáveres adiados. São Paulo: Atlas, 2013.

PISAPIA, Gian Domenico. Compendio di procedura penale. 4. ed. Padova: Cedan, 1985.

MAZZUOLI, Valério de Oliveira. In: CANOTILHO, J. J. Gomes. MENDES, Gilmar Ferreira. SARLET, Ingo Wolfgang. STRECK, Lenio Luiz. LEONCY, Léo Ferreira (Cord.). Comentários à Constituição do Brasil. 1 ed. São Paulo: Saraiva, 2014, p. 518-524.

MAZZUOLI, Valério de Oliveira. Controle jurisdicional da convencionalidade das leis. 5 ed. Rio de Janeiro: Forense, 2018.

PIOVESAN, Flávia. Direitos humanos e o direito constitucional internacional. 18 ed. São Paulo: Saraiva Educação, 2018.

RESCHER, Nicholas. Epistemology: an introduction to the theory of knowledge. New York: NY University Press, 2003. 
ROCCO, Alfredo. The Political Doctrine of Fascism. Disponível em < https://www.stephenhicks.org/2017/06/05/roccos-the-political-doctrine-of-fascism/>. Acesso em 18.07.2020.

SARLET, Ingo Wolfgang. Marinoni, Luiz Guilerme. MITIDIERO, Daniel. Curso de Direito Constitucional. 2 ed. São Paulo: Revista dos Tribunais, $2013 a$.

As dimensões da dignidade da pessoa humana: construindo uma compreensão jurídicoconstitucional necessária e possível. In: MAURER, Beatrice et al. Dimensões da dignidade: ensaios de filosofia do direito e direito constitucional. Porto Alegre: Livraria do Advogado, 2013 b, p. $15-43$.

In: CANOTILHO, J. J. Gomes. MENDES, Gilmar Ferreira. SARLET, Ingo Wolfgang. STRECK, Lenio Luiz. LEONCY, Léo Ferreira (Cord.). Comentários à Constituição do Brasil. 1 ed. São Paulo: Saraiva, 2014, p.516-518.

SCHMITT, Carl. Der Führer schütz das Recth. Disponível em 〈http://delete129a.blogsport.de/images/CS DerFuehrerschuetztdasRecht.pdf〉. Acesso em 18.07.2020.

Supremo Tribunal Federal. Recurso Extraordinário no 466343 SP, Relator: Min. CEZAR PELUSO, Data de Julgamento: 03/12/2008, Tribunal Pleno, Data de Publicação: DJe-104 DIVULG 04-06-2009 PUBLIC 05-06-2009 EMENT VOL-02363-06 PP-01106 RDECTRAB v. 17 , n. 186,2010 , p. 29-165. 